\title{
UMA ANÁLISE DOS SIGNIFICADOS DE CONSUMO DE VINHO NO CONTEXTO DE UMA CONFRARIA FEMININA
}

\section{AN ANALYSIS OF THE MEANINGS OF CONSUMPTION OF WINE IN A WINE ASSOCIATION FOR WOMEN CONTEXT}

Data de submissão: 22/01/2014

Aceite: $14 / 07 / 2015$

Mariana Bertuol ${ }^{1}$

Claudio Hoffmann Sampaio ${ }^{2}$

Marcelo Gattermann Perin ${ }^{3}$ Marcia Horowitz Vieira ${ }^{4}$

\section{RESUMO}

A utilidade dos produtos não é o único fator determinante nas decisões de compra dos consumidores, na medida em que os significados simbólicos carregados pelos bens também exercem papel fundamental nesse processo. Estes significados podem ser tanto idiossincráticos, quanto comumente partilhados com outros consumidores. Além disso, podem ser utilizados pelos indivíduos para sustentar a sua imagem ou criar uma nova representação de si mesmos. O presente estudo buscou entender o processo de construção de significados agregados ao consumo de vinhos por um grupo de mulheres que dividem hábitos, compartilham gostos, opiniões e deram origem à formação de uma confraria do vinho na Serra Gaúcha. Assim, este artigo teve como principal objetivo entender o papel de uma confraria feminina no processo de construção dos significados de consumo do vinho. A fim de atingir o propósito do estudo, uma pesquisa qualitativa e exploratória foi conduzida. Dentre os principais resultados, constatou-se que a confraria exerce papel fundamental na mudança do estilo de vida das participantes. Por meio dela, as mulheres reafirmam o seu papel na sociedade, conquistando o seu espaço em uma área tradicionalmente dominada pelos homens.

Palavras-Chave: Significados de Consumo. Vinho. Confraria Feminina.

1 Possui graduação em Administração de Empresas com ênfase em Comércio Internacional, mestrado em Administração e Negócios pela Pontifícia Universidade Católica do Rio Grande do Sul. Recentemente concluiu uma pós graduação na área de marketing pela Universidade da Califórnia, Berkeley. Porto Alegre. Rio Grande do Sul. Brasil. E-mail: maribertuol@hotmail.com

2 Possui graduação em Administração de Empresas e em Administração Pública pela UFRGS, mestrado e doutorado pela Universidade Federal do Rio Grande do Sul (UFRGS). Pós-doutor em Marketing pela University of Georgia (EUA). Atualmente é professor titular da Pontifícia Universidade Católica do Rio Grande do Sul, atuando nos cursos de Mestrado e de Doutorado em Administração do Programa de Pós-Graduação em Administração (PPGAd). Porto Alegre. Rio Grande do Sul. Brasil. E-mail: csampaio@pucrs.br

3 Possui graduação em Ciências da Computação pela Universidade Federal de Santa Catarina e graduação em Administração de Empresas pela Fundação Armando Álvares Penteado. Mestrado em Ciências da Computação pela Universidade Federal do Rio Grande do Sul e doutorado em Administração pela Universidade Federal do Rio Grande do Sul. Atualmente é professor titular nos cursos de Mestrado e Doutorado do Programa de Pós-Graduação em Administração da Pontifícia Universidade Católica do Rio Grande do Sul, e coordenador do Comitê de Assessoramento de área do CNPq. Porto Alegre. Rio Grande do Sul. Brasil. E-mail: mperin@pucrs.br

4 Possui bacharelado em Comunicação Social - Relações Públicas pela PUCRS, mestrado em Administração e Negócios - Marketing na FACE/PPGAd/PUCRS e mestrado em Business and Management pela Anglia Ruskin University - Cambridge/Inglaterra. Doutoranda em Administração - Marketing na FACE/PPGAd/PUCRS. Atualmente é professora da Faculdade de Comunicação Social (FAMECOS). Porto Alegre. Rio Grande do Sul. E-mail: marcia.horowitz@gmail.com 


\section{ABSTRACT}

The products usefulness it is not the only decisive factor when consumers are deciding whether to buy or not a product, given the fact that the symbolism behind the products meaning also play an important role in this process. These meanings can be idiosyncratic as it can be shared by other consumers. Besides it can be used by the individuals to maintain their identity or to create a whole new identity to represent themselves in the eyes of the society. This study aimed to understand the construction process of the meaning of wine consume by a group of women who share habits, tastes and opinions which lead to the creation of a wine association for women only, in the "Serra Gaucha". This article's main objective was to understand the women's wine association influence over the construction process of the meanings of wine consumption. In order to achieve this study purpose, a qualitative and exploratory research was conducted. Between the main results of this research, it is clear how the wine association for women plays a key role in its member life style change. Trough the association, women reaffirm themselves and their role in the society, conquering their share of the pie in a normally men dominated environment.

Keywords: Meanings of Consumption. Wine. Wine Association for Women.

\section{INTRODUÇÃO}

Nos últimos vinte anos, as pesquisas na área de comportamento do consumidor têm se direcionado intensamente a aspectos socioculturais, experienciais, simbólicos e ideológicos de consumo (ARNOULD; THOMPSON, 2005). O desenvolvimento desses estudos nada mais é do que o reflexo de um dos papéis que o consumo exerce na nossa sociedade, ou seja, o de servir de caminho para que indivíduos e grupos sejam capazes de interpretar, transformar, resistir e modificar padrões culturais e significados previamente estabelecidos. O consumo deixou de ser definido como uma pequena fatia do indivíduo, sendo mais frequentemente definido como um conjunto de fenômenos diversos, sistemáticos, abrangentes e plenamente culturais (MCCRAKEN, 2003; PINTO, 2013; LEVY, 1981; MICK, 1986; ROOK, 1985; SOLOMON, 1983; WELLS, 1986). Nesse sentido, de acordo com Mooij e Hofstede (2011), muitos aspectos do entendimento dos mercados consumidores não são individualmente explicados, mas culturalmente constituídos e determinados.

Assim, as decisões de consumo são tomadas não apenas pela utilidade dos produtos, mas também pelos significados simbólicos que eles carregam (ALTAF; TROCCOLI; MOREIRA, 2013). Esses significados podem ser tanto idiossincráticos, como comumente partilhados com outros consumidores (WATTANASUWAN, 2005). Na medida em que esses significados vão sendo transferidos do mundo cultural para os objetos, eles são passados para os consumidores que extraem dos objetos os novos significados (MCCRACKEN, 2003; VELLIQUETTE; MURRAY; CREYER, 1998). Como decorrência, cresce a importância do tema significados de consumo (MOOIJ; HOFSTEDE, 2011), inclusive no Brasil (DALMORO, 2014; WESTPHAL; ACEVEDO, 2014). Sáenz-Navajas et al. (2014) apontam que há um crescente interesse da indústria de alimentação em geral e, particularmente, da indústria de vinhos em entender os significados associados ao vinho (MARKS, 2011), possibilitando aos produtores melhorar as estratégias de seus produtos para atender os distintos mercados. Nesse sentido, é necessário focar tanto nas propriedades do produto em si, quanto nas representações simbólicas desejadas pelos consumidores.

Nessa linha de pesquisa sobre significados simbólicos recai o objetivo deste estudo e principal contribuição acadêmica, procurando entender o papel de uma confraria feminina de vinhos localizada na Serra Gaúcha no processo de construção dos significados de consumo do vinho, buscando compreender, assim, o papel dos grupos na transferência de significados do mundo culturalmente constituído. Como justificativa, destaca-se a presença de dois importantes fenômenos. 
O primeiro diz respeito às mudanças nos hábitos de consumo dos brasileiros em relação ao vinho, o qual passou a ser mais bem aceito e mais acessível para um número maior de consumidores. Segundo dados do Instituto Brasileiro de Vinhos (IBRAVIN), há um acréscimo de vendas de vinhos brasileiros nos últimos anos, registrando só em 2013 um crescimento de 10,7\% em relação ao ano anterior. O segundo fenômeno se refere aos grupos de consumo, as chamadas "confrarias do vinho", que organizam encontros periodicamente nos quais o objetivo e o tema central são o vinho. Nesses encontros são realizadas atividades como: degustações, palestras com enólogos e fabricantes, visitas em cantinas da região e até viagens para outros países produtores de vinhos. Além de incentivar o convívio social, a apreciação ao vinho promove a troca de experiências e o aprendizado sobre o universo histórico-cultural da bebida (Federação Brasileira de Confrarias e Associações Femininas do Vinho e do Espumante - FEBAVE, 2010), em decorrência novos grupos de consumidores e formadores de opiniões se desenvolvem, incentivando o consumo de vinho e interferindo em seu significado simbólico.

\section{SIGNIFICADOS DE CONSUMO}

O sistema de signos e símbolos vinculado aos objetos nunca foi tão forte e tão representativo da ordem social. Essa é a característica que diferencia a sociedade contemporânea das suas antecessoras: o mundo do consumo é uma rede de signos e significados interligados e interdependentes e oferece um modo de socialização aos seus indivíduos (BAUDRILLARD, 1981). Seguindo esse pensamento, McCracken (2003) afirma que os produtos são depositários de significados culturais que podem estar evidentes ou escondidos para o consumidor; eles possuem uma significação que vai além do seu caráter utilitário e de seu valor comercial (FERRAZ; REBOUÇAS; QUEIROZ; ROCHA, 2014).

Para Ahuvia (2005), Tian e Belk (2005) e Wattanasuwan (2005), os consumidores procuram nos produtos os significados que eles necessitam para construir ou sustentar a imagem que eles têm ou gostariam de ter deles mesmos. Assim, além da sua função utilitária, os objetos expressam a identidade do indivíduo. Ahuvia (2005) vai ainda mais além, sugerindo que o consumo de certos objetos pode contribuir ou amenizar um conflito interno, possibilitando ao indivíduo sintetizar as identidades opostas para que consiga viver o melhor de ambos os mundos. Ainda, para Wattanasuwan (2005), a formação da identidade ou adoção de determinado estilo de vida implica em resistir e abandonar o consumo de certos produtos.

Segundo o modelo criado por Hirschman, Scott e Wells (1998), a construção do significado se dá por meio de relações recíprocas entre texto, prática e história. $O$ texto refere-se ao conteúdo das propagandas, que engloba informações sobre os produtos. A prática está relacionada com os aspectos da vida cotidiana, costumes, hábitos, estilos e vida e pontos de vista. Finalmente, a história diz respeito ao passado vivido pela sociedade. Os autores afirmam que essas três variáveis são capazes de criar e de receber novos significados.

Mick e Buhl (1992), por sua vez, enfatizam o papel ativo do consumidor na construção do significado, ou seja, o indivíduo cria o significado por meio de sua interpretação em relação aos anúncios que recebe. Esta interpretação é influenciada pelos: (1) Life Themes, que constituem nos paradigmas que foram formados por meio da conjuntura sociocultural na qual o indivíduo nasceu e se desenvolveu, e (2) Life Projects, que se referem às orientações específicas de cada indivíduo, sendo compostas por quatros esferas distintas de acordo com o contexto de cada pessoa: nacionalidade, comunidade, família e self íntimo (MICK; BUHL, 1992). Enfim, de acordo com o modelo proposto pelos autores, os consumidores se baseiam em seus projetos e temas de vida para atualizar e criar os significados conotativos dos anúncios. 
Conforme McCraken (2003), uma das maiores limitações das abordagens sobre significados culturais dos bens de consumo era que as mesmas falhavam em observar que este significado está em constante trânsito. Ou seja, ele flui ininterruptamente em direção as suas diversas localizações no mundo social. Com o objetivo de preencher essa lacuna, na década de 80, o autor propôs um modelo teórico. Por meio de uma estrutura definida, o modelo apresenta a qualidade móvel do significado dos bens de consumo: de onde ele veio, para onde vai e como foi transferido. Segundo o autor, os significados atribuídos aos bens de consumo carregam e comunicam significados culturais, os quais estariam localizados no mundo culturalmente constituído, nos bens de consumo e no consumidor como pessoa. Os significados seriam transferidos do mundo culturalmente constituído para os bens de consumo por meio da propaganda e do sistema de moda, e, a partir daí, seriam transferidos dos bens para o consumidor por meio de rituais de consumo.

Seguindo os conceitos de McCracken (2003, p. 101), o mundo culturalmente constituído é "o mundo da experiência cotidiana por meio do qual o mundo dos fenômenos se apresenta aos sentidos do indivíduo". Esse, por sua vez, é completamente moldado e constituído pelas crenças e conjeturas de sua cultura. A cultura determina as "lentes" que cada indivíduo utiliza para enxergar o fenômeno, ou seja, a cultura em que se está inserido acaba por definir a forma de enxergar o mundo. Em segundo lugar, a cultura também funciona como "plano de ação" da atividade humana, uma vez que ela determina as coordenadas da ação social e da atividade produtiva, definindo os comportamentos e objetos que dela fazem parte. A jornada do significado por meio do mundo social finaliza no momento em que ele finalmente se assenta no consumidor. Este significado é usado para definir e orientar o indivíduo, o qual possui total liberdade para extrair do bem o significado que deseja (MCCRACKEN, 2003).

Como pode ser observado no modelo de McCracken (2003), os significados são transferidos do mundo culturalmente constituído para os bens de consumo por meio das instituições da publicidade e do sistema de moda. Corroborando com a idéia de Domzal e Kernan (1992) citada anteriormente, McCracken (2003) afirma que a publicidade atua como potente método de transferência de significado agregando os dois elementos de tal modo que o consumidor vislumbre uma similaridade essencial entre eles. Quando esta equivalência simbólica é efetuada com sucesso, o consumidor atribui ao bem de consumo certas propriedades existentes no seu mundo culturalmente constituído. Já o sistema de moda é considerado por McCracken (2003) menos observado e compreendido como um instrumento de movimentação de significados. Ele pode atuar de três maneiras: por meio da mídia da mesma forma que a publicidade atua, inventando novos significados por meio de celebridades ou líderes de opinião e, por último, por meio de reformas radicais.

Após essa transferência de significados do mundo culturalmente constituído para os bens de consumo, esses se tornam o lócus do significado cultural. Por meio dos rituais de troca, posse, arrumação e despojamento, o significado é movido do bem de consumo para o consumidor individual. O ritual é "uma oportunidade para afirmar, evocar, assinalar ou revisar os símbolos e significados convencionais da ordem cultural" (MCCRACKEN, 2003, p.114). A jornada do significado por meio do mundo social finaliza no momento em que ele finalmente se assenta no consumidor. Este significado é usado para definir e orientar o indivíduo, o qual possui total liberdade para extrair do bem o significado que deseja (MCCRACKEN, 2003). Enfim, há uma absoluta identificação entre símbolo e indivíduo e os símbolos não mais representam a pessoa, mas sim se transformam na pessoa (VELLIQUETTE; MURRAY; CREYER ,1998). Apesar das críticas apresentadas ao modelo de McCraken (1986), em especial quanto a sua estrutura linear rígida (SOLOMON, 1983; THARP; SCOTT, 1990; MICK; BUHL, 1992; MICK et al, 2004; MCKECHNIE; TYAN, 2006) e à ideia de que o consumidor não é apenas um simples receptor de significado (SOLOMON, 1983; 
THARP; SCOTT, 1990; MICK et al, 2004; MCKECHNIE; TYAN, 2006), é evidente que o estudo de McCracken (1986) representou um marco na teoria sobre significados dos bens de consumo na medida em que analisa o processo de transferência e movimento dos significados, o qual era negligenciado pela academia até determinada data.

A partir desta ótica, de que o consumo não é apenas racional, uma série de estudos foi desenvolvida para tentar identificar o significado dos produtos na perspectiva dos consumidores. Dentre algumas dessas pesquisas, foram levantados significados para o consumo e uso de: cigarro, licor e cerveja (DOMZAL; KERNAN, 1992), tatuagens (VELLIQUETTE; MURRAY; CREYER, 1998), roupas íntimas femininas (AMY-CHINN; JANTZEN; OSTERGAARD, 2006), batom (MERSKIN, 2007), café (HIRSCHMAN; SCOTT; WELLS, 1998) entre outros.

De acordo com Sáenz-Navajas et al. (2013), a percepção de qualidade do vinho é um construto multidimensional que tem recebido interesse especial nos últimos anos, sendo entendida como uma combinação de fatores relacionados ao produto e relacionados ao consumidor. Os fatores relacionados ao produto têm sido classificados em duas principais categorias: intrínsecas (propriedades sensoriais do vinho) e extrínsecas (propriedades que não fazem fisicamente parte do vinho como região, ano, produtor). Assim, muitos estudos têm investigado a importância de diferentes aspectos relacionados ao vinho: país de origem (VEALE; QUESTER, 2009), informações sobre rótulo (MUELLER et al., 2010), estética do rótulo (CHREA et al., 2011), prêmios recebidos (CHREA et al., 2011), engarrafador (SÁENZ-NAVAJAS et al., 2013).

Já os fatores relacionados ao consumidor são indiretamente relacionados ao vinho, mas determinantes na construção cognitiva da qualidade do vinho e de seu significado (SÁENZ-NAVAJAS et al., 2014). Nessa linha, muitos estudos relacionados à alimentação reportam a importância da cultura do consumidor na avaliação dos alimentos, explorando os efeitos culturais nas avaliações hedônicas e de percepção (SÁENZ-NAVAJAS et al., 2013) e, mais especificamente, da importância da construção simbólica dos consumidores no mercado de vinho (MARKS, 2011).

Assim, muitos estudos contemporâneos buscam compreender preferências de vinhos em distintas culturas/países (SÁENZ-NAVAJAS et al., 2013; WILLIAMSON; ROBICHAUD; FRANCIS, 2012; TORRI; NOBLE; HEYMANN, 2013). Marks (2011) aponta as mudanças da produção internacional de vinho nas últimas três décadas com o rápido crescimento de mercados não tradicionais, sugerindo como uma explicação a natureza do vinho no mercado como um bem cultural carregado de significados. Entretanto, a despeito desses estudos, McCracken (2012) declara haver espaço para investigações que investiguem particularmente o papel de grupos específicos - como uma confraria - na transferência de significados do mundo culturalmente constituído.

\section{MÉTODO}

Para o presente estudo, optou-se por uma pesquisa qualitativa e exploratória (GILL, 2002). Como se buscava entender o papel dos grupos e da interferência da interação com outras pessoas na construção dos significados de consumo, escolheu-se como lócus da investigação a Confraria do Vinho e da Champanha das Mulheres de Bento Gonçalves (CVCM - BG), a qual possui mais de dez anos de existência e é composta por mulheres da região da Serra Gaúcha. A escolha das consumidoras deu-se por entender que as mesmas ainda não possuíam consolidados os significados de consumo do vinho, e que a confraria interferiu no processo de movimentação e construção dos significados culturais de consumo. A seguir, são descritas as etapas seguidas para o desenvolvimento do estudo que ocorreram durante os anos de 2010 e 2012. 


\section{ETAPA 1: ANÁLISE DOCUMENTAL}

Iniciou-se a investigação por meio da literatura visando um aprofundamento do conhecimento sobre o tema. A partir dessa análise, procurou-se identificar no contexto analisado - a confraria feminina - alguns agentes influenciadores no processo de construção e movimento de significados apontados na teoria.

A propaganda, destacada por McCracken (1986), sem dúvida nenhuma exerce papel fundamental na transferência e criação de significados, entretanto, conforme exposto por Solomon (1996), a produção de cultura não se dá apenas por meio do sistema de comunicação, mas também pelos subsistemas: criativo e gerencial. Nesse sentido, os elementos que permeiam a realidade da confraria analisada são as propagandas encontradas na mídia e também o sistema de produção de cultura, ou seja, indivíduos e organizações responsáveis pela criação e marketing do produto (SOLOMON, 1983). Sendo assim, decidiu-se analisar as propagandas de vinho e buscar uma aproximação com os responsáveis pelo marketing de algumas empresas.

Como o mercado de vinhos é muito amplo, apresenta uma variedade enorme de produtos e marcas nacionais e importadas, delimitou-se esta etapa de análise documental de acordo com alguns critérios. $O$ primeiro se refere à restrição do estudo a categoria de vinhos finos, que são os vinhos consumidos nos encontros da confraria, incluindo os tintos, brancos e espumantes. Em segundo lugar, embora a confraria também utilize vinhos estrangeiros em seus eventos, o grupo incentiva muito a apreciação dos vinhos brasileiros, desta forma, optou-se por investigar as propagandas somente das marcas nacionais.

Assim, foram consultadas as homepages das mais importantes empresas do setor, bem como os principais meios de comunicação, como a televisão e os jornais e revistas de maior circulação no Rio Grande do Sul. Destaca-se que a maior parte das propagandas e campanhas foi encontrada na Internet, em sites e revistas especializadas e nas homepages das empresas.

Assim, foram elencadas as principais empresas do setor em tamanho e representatividade - Aurora, Miolo e Salton - junto a outras que surgiram com mais freqüência nas mídias (revistas, jornais, televisão e outdoors) - Casa Perini, Casa Valduga, Cave Geisse, Dal Pizzol e Chandon do Brasil. Também foram analisadas as campanhas dos Vinhos do Brasil, que não consiste em uma empresa específica, mas sim em uma marca criada para caracterizar e divulgar os vinhos brasileiros.

\section{ETAPA 2: ENTREVISTAS EM PROFUNDIDADE E OBSERVAÇÃO PARTICIPANTE NA CONFRARIA}

Em relação aos elementos que proporcionam a interação social entre os consumidores rituais de consumo para McCracken (1986), guardiões culturais para Solomon (1996) ou instituições culturais para Tharp e Scott (1990), optou-se por tentar entender a sua dinâmica no grupo por meio de entrevistas em profundidade e de observação participante nos encontros da confraria.

O primeiro contato com a confraria se deu por meio de uma das fundadoras do grupo que relatou a história da confraria, indicou diferentes participantes para participarem do estudo, bem como forneceu uma série de documentos e registros, tais como: estatuto da confraria, atas e fotos dos encontros, depoimentos das confreiras, registros de cursos, palestras, visitas a cantinas e viagens. Esses materiais, juntamente com entrevistas em profundidade com três participantes da confraria, serviram de base para as primeiras percepções e para o entrosamento com as mulheres da confraria. As Confreiras entrevistadas inicialmente fazem parte do grupo desde a sua fundação, por isso, visando agregar mais informações para analisar o papel da confraria no processo de construção dos significados, outras entrevistas foram conduzidas com mulheres que 
possuam tempos de participação diferentes na confraria. Ao invés de contar opiniões ou pessoas, a entrevista qualitativa busca explorar o espectro de opiniões e as diferentes representações sobre o assunto a ser analisado (BARDIN, 2000). Desta forma, mais nove entrevistas foram conduzidas com outras participantes da confraria, totalizando 12 entrevistas.

Para a realização das entrevistas, um roteiro semiestruturado foi elaborado, que foi construído com base nos objetivos deste estudo e, antes de sua aplicação, o mesmo foi validado por três professores pesquisadores sobre o tema. As entrevistas foram realizadas pessoalmente, e duraram, em média, de trinta minutos a uma hora e trinta minutos. Abaixo, é apresentada a relação das entrevistadas e suas principais características:

\begin{tabular}{|c|c|c|c|}
\hline Entrevistadas & Estado Civil & Profissão & Tempo de Confraria \\
\hline 1 - M. Luiza & Casada & Gerente Comercial & 10 anos \\
\hline 2 - Sandra F. & Casada & Secretária & 10 anos \\
\hline 3- Maysa & Casada & Professora & 10 anos \\
\hline 4- Sonia & Solteira & Pediatra & 10 anos \\
\hline 5- Nica & Casada & Professora Aposentada & 10 anos \\
\hline 6 - M. Alice & Casada & Empresária do ramo hoteleiro & 10 anos \\
\hline 7- Lizete & Solteira & Empresária & 4 anos \\
\hline 8 - Sandra Z. & Viúva & Empresária & 10 anos \\
\hline 9- Carmem & Casada & Administradora & 2 anos \\
\hline $10-$ Magda & Casada & Funcionária pública & 6 anos \\
\hline $11-$ Aidana & Casada & Fonoaudióloga & 10 anos \\
\hline 12- Lui & Casada & Dona de casa & \\
\hline
\end{tabular}

Quadro 1 - Relação de entrevistadas

Fonte: elaborado pelos autores com base na pesquisa de campo

A observação participante é uma técnica que permite "o contato direto do pesquisador com o fenômeno observado para obter informações sobre a realidade dos atores sociais em seus próprios contextos" (CRUZ NETO, 1994, p. 59), assim, optou-se por incrementar a coleta por meio da realização de observação participante em alguns dos encontros organizados pela confraria. Os encontros da confraria são realizados mensalmente, geralmente na primeira terça-feira de cada mês. Nesse sentido, um dos autores do estudo participou de oito encontros que trataram dos seguintes temas: influência do clima na safra de vinho, tendências do setor vitivinícola, defeitos dos aromas, harmonização, harmonização de vinhos com fondue, culinária e vinhos gregos, degustação de vinhos da Domno Brasil, degustação de vinhos da região de Flores da Cunha. Ao final desses oito encontros obteve-se uma repetição de fatos, possibilitando um entendimento mais profundo do fenômeno investigado. $O$ uso conjunto das entrevistas e da observação participante visa uma aproximação mais significativa do campo a ser estudado, que se caracteriza justamente pela complexidade dos fenômenos.

\section{ETAPA 3: ENTREVISTAS COM ESPECIALISTAS}

Com o intuito de entender melhor o fenômeno, verificando qual é a postura das empresas perante os grupos específicos de consumo - como as confrarias femininas de vinho - e o que as empresas entendem por significados de consumo, decidiu-se realizar entrevistas com gestores de algumas fabricantes de vinho nacionais. O sistema de produção cultural exerce papel fundamental no processo de construção de significados (SOLOMON, 1983). Assim, além de analisar o material das propagandas e anúncios das marcas de vinhos, acredita-se que seja necessário 
também, investigar a visão dos profissionais nas empresas perante esse contexto dos significados culturais do vinho e do fenômeno das confrarias.

No quadro abaixo são apresentadas as empresas e a experiência de cada especialista entrevistado.

\begin{tabular}{|c|c|c|}
\hline Especialista & Cargo / Empresa & Experiência \\
\hline $\mathbf{1}$ & Diretor Executivo / Vinícola Salton & $\begin{array}{c}\text { 8 anos como pesquisador de enologia na Europa } \\
\text { e EUA, 28 anos na empresa atual }\end{array}$ \\
\hline $\mathbf{2}$ & Diretor Técnico / Chandon do Brasil & $\begin{array}{c}24 \text { anos na empresa atual, sendo 2 anos na Fran- } \\
\text { ça, 1 ano na Argentina e 21 anos no Brasil }\end{array}$ \\
\hline $\mathbf{3}$ & Diretor / Vinícola Don Laurindo & $\begin{array}{c}33 \text { anos como enólogo, sendo 20 anos como di- } \\
\text { retor e sócio da empresa atual }\end{array}$ \\
\hline $\mathbf{4}$ & Proprietário / Vinícola Don Giovanni & $\begin{array}{c}10 \text { anos como pesquisador na área de tecnologia } \\
\text { voltada para a vitivinicultura, 28 anos como pro- } \\
\text { prietário da empresa atual }\end{array}$ \\
\hline
\end{tabular}

Quadro 2 - Relação de especialistas

Fonte: elaborado pelos autores com base na pesquisa de campo

\section{APRESENTAÇÃO, DISCUSSÃO E ANÁLISE DOS RESUL- TADOS}

Para alcançar os resultados do estudo aplica-se a análise de conteúdo, que consiste no conjunto de procedimentos de análises das verbalizações obtidas durante as entrevistas em profundidade e observação participante. Seguindo este procedimento de análise, o pesquisador se vale de técnicas sistemáticas e precisas para descrever as informações contidas em uma mensagem, ou seja, esta técnica trata-se da inferência de dados oriundos da produção e da recepção do que foi comunicado, dito e falado (BARDIN, 2000). A análise de conteúdo adapta-se a este estudo, pois após a coleta dos dados junto às entrevistas em profundidade, os conteúdos, as falas e experiências foram categorizadas, ou seja, os relatos das participantes da confraria e dos especialistas são explorados, organizados e separados em categorias, aquelas considerando os objetivos do estudo. Estas são denominadas categorias a priori (BARDIN, 2000) que neste estudo são: hábitos das mulheres em relação ao vinho, significados do vinho sob a ótica das confreiras, significados do vinho apresentados pelas empresas, e por fim o papel da confraria no processo de construção dos significados. A discussão dos resultados inicia com a descrição dos hábitos de consumo das participantes e dos significados de consumo do vinho sob a ótica das integrantes do grupo. Logo após, são expostos os significados encontrados na publicidade e, por fim, é abordada a opinião dos especialistas e a influência do grupo na construção dos significados de consumo.

\subsection{OS HÁBITOS DE CONSUMO - ANTES E DEPOIS DA CONFRARIA}

Visto que a confraria estimula o contato das mulheres com tudo o que diz respeito ao vinho, consequentemente, os hábitos das confreiras em relação ao vinho podem ser divididos entre os hábitos de consumo antes da confraria e depois da confraria.

Em primeiro lugar, muitas mulheres afirmaram que não tinham o costume de beber um vinho quando estavam sozinhas. Quando saíam para jantar ou ir em algum evento, geralmente apenas bebiam na companhia de amigos ou de alguém do sexo oposto. Em casa, todas comentam que o consumo era bem mais esporádico antes da confraria. Depois da confraria, muitas mulheres adotaram o hábito de beber vinho quando estão em casa. 
A relação do vinho com o pratos que seriam feitos para combinar com a bebida foi outro aspecto levantado pelas mulheres nas entrevistas em relação à mudança de hábitos, visto que muitas delas afirmaram que antes da confraria não prestavam atenção para os detalhes da harmonização. Depois de aprender e experienciar diferentes combinações, elas começaram a adotar esta prática nas suas vidas cotidianas.

Outra mudança foi de que, as mulheres que tinham o hábito de consumir muito vinho afirmam ter diminuído a quantidade consumida após ingressar na confraria, enquanto as que bebiam menos ou quase não bebiam confessam que passar a consumir mais. Isso se deu porque, elas passaram a ser mais seletivas, aprenderam a saborear o vinho com mais cautela, prestando a atenção na sua qualidade, características e aromas, passando assim, a rejeitar alguns vinhos que não condizem com o seu paladar. Seguindo esta linha, detectou-se também que as mulheres atualmente degustam com muito mais qualidade e prazer do que em anos anteriores, quando não participavam da confraria. É uma diferente forma de consumo, pois é uma maneira mais consciente e de maior apreciação, mais relacionada ao prazer:

Tomava e tomo vinho quase de diariamente, mas depois de ingressar na confraria aprendi a apreciar com mais cuidado e atenção observando seus aromas, cores, origem, enfim, características (NICA).

O hábito de procurar coisas novas, ir atrás de lançamentos, vinhos diferentes e de outros locais também foi adquirido com o tempo de confraria. Muitas mulheres relatam que antes da confraria costumavam escolher sempre os mesmos vinhos e que agora elas se sentem motivadas a ir a busca de novos tipos.

Por fim, o último aspecto verificado em relação aos hábitos foi a mudança de paladar que algumas mulheres afirmaram ter percebido como uma mudança depois da vivência na confraria. Com a evolução do entendimento sobre os seus gostos e paladar, algumas confreiras mudaram as até suas preferências por certos produtos. Assim, pode-se observar que a confraria realmente influenciou na mudança de muitos hábitos de consumo das mulheres em relação ao vinho. Como principais hábitos antes da confraria pode-se destacar: beber sempre na companhia de outras pessoas; não associar o vinho ao tipo de comida; beber sem critérios ou quase não beber; consumo inconsciente; beber sempre os mesmos vinhos e paladar menos apurado e limitado. Baseados nisso, algumas mudanças foram observadas: beber com companhia ou mesmo sozinhas; praticar a harmonização dos pratos com os vinhos; beber com cautela e com mais seleção na escolha; consumo mais consciente ligado ao bem-estar, prazer e qualidade de vida; buscar novos produtos, experimentar novas opções e paladar mais aguçado, implicando na mudança de preferências.

\subsection{SIGNIFICADOS DO VINHO SOB A ÓTICA DAS PARTICIPANTES DA CONFRARIA}

A seguir são apresentados os significados encontrados por meio das entrevistas e observação participante na confraria.

\section{INTELECTUALIDADE/CONHECIMENTO}

O vinho, na vida dessas mulheres, se tornou um símbolo de conhecimento, de intelectualidade. Para elas, o fato de estudarem as propriedades do vinho, torna-as mais cultas, mais interessantes e mais bem resolvidas. No relato a seguir nota-se essa relação: 
Hoje em dia se me convidassem para entrar numa turma de carteado ou bordado, eu não aceitaria! Claro, talvez não tenha essas aptidões (risos). Já uma confraria de vinhos te faz usar a cabeça, querer estudar, ler sobre o assunto, [...] tu te sente mais ligada no que tá acontecendo, nas tendências. [...] Isso agrega conhecimento, faz parte de todo um aprendizado! (MAYSA).

Assim, toda essa bagagem de aprendizado vai dando às mulheres a força do conhecimento, elas se sentam aptas a discutir sobre o assunto sem temores em qualquer ambiente. E o mais importante, elas sentem prazer ao fazer isso. O significado de intelectualidade também está muito relacionado à imagem que as mulheres passam para os seus amigos e familiares. Por meio do vinho, elas conseguem demonstrar que são mais inteligentes e conhecedoras do assunto. Por fim, a intelectualidade também proporciona o aumento da autoestima das mulheres.

\section{PODER}

Este significado foi o menos expressado de forma verbal e direta, mas demonstrou estar muito presente nas confreiras. Primeiramente, o poder está relacionado com a reafirmação do papel da mulher na sociedade, ou seja, beber e entender sobre vinhos the dá a chance de conquistar um espaço em uma área tradicionalmente dominada pelos homens. No relato abaixo, Maria Luiza expressa essa sensação:

As mulheres também quiseram entender mais, opinar mais [...] com certeza!! Ai, eu acho que é uma coisa bem boa, sabe, que meu marido antes de fazer medicina ele fez enologia, meu marido é enólogo. Mas, hoje em dia, para qualquer restaurante que a gente vai, ou mesmo, quando tô fazendo a janta e ele me diz assim: - E hoje, que vinho vamos beber? Com freqüência sou eu que escolho! (MARIA LUIZA).

Em segundo lugar, o poder pode estar relacionado à sensação de independência e autonomia das mulheres.

Umas das coisas que eu achei legal com o passar do tempo, foi me sentir mais a vontade para escolher um vinho por minha conta, sem depender da opinião do meu marido ou de outras pessoas. [...] E melhor ainda, depois de sugerir um vinho, é ver que a decisão agradou (MAYSA).

\section{PRAZER}

O prazer foi um dos significados mais evidentes nas confreiras. O prazer no sentido de relaxamento, de estar de bem com a vida, da alegria de curtir aquele momento especial, que é o de degustar um bom vinho. É importante salientar que esse prazer não está ligado ao efeito do álcool, mas sim, na sutileza do sabor, do aroma e de toda a magia relacionada ao vinho. Além disso, o vinho representa um elemento benéfico, saudável e até terapêutico. $O$ vinho está diretamente relacionado a bons momentos, ou seja, momentos de prazer. Além disso, o vinho pode ser percebido como um símbolo de alegria e felicidade, salientando que este sentimento de bem estar inicia antes mesmo de seu consumo. Percebe-se que o prazer relacionado ao vinho engloba todo o processo de compra, desde o momento da escolha.

Mmmn... vou te dizer o que o vinho representa... Uma coisa muito boa! Um momento, a felicidade, "vamos tomar um vinho, ai q bom, que vinho?", então é um momento de descontração e de alegria, porque no momento que a gente vai escolher também é muito 
prazeroso! "ai, que vinhos nós vamos tomar, ai que delícia, lembra tal lugar que a gente tomou aquele vinho", então lembra, traz recordações, sabe, então, é um momento de descontração e alegria, a escolha de um vinho é sempre muito boa (M ALICE).

\section{DESAFIO}

Constatou-se que o vinho em si, representa um grande desafio para as mulheres. $\mathrm{O}$ desafio de querer aprender mais, conhecer mais e vivenciar mais. Quanto mais elas vão entendendo sobre o assunto, mais elas querem evoluir e se aprimorar. A motivação aumenta e elas continuam empenhadas a buscar sempre mais. $\mathrm{E}$, conforme o relato abaixo, esse desafio é para a vida toda.

[...] nem que se fossemos daqui a 30 anos nos encontrarem tomando uma sopa, um creminho, mas sempre apreciando um bom vinho, [...] podemos ser experts, como essa mulher, a Isolda, que foi uma mulher mais expert, ela gostava de vinho, morreu aos 90 anos, e ela fazia parte de confrarias, ia a encontros de confraria na França que é uma confraria que, acho que, se reúne uma vez por ano, uma confraria seleta, e justamente por toda essa motivação que o vinho traz (SANDRA).

\section{SOCIALIZAÇÃO}

A socialização é um dos significados mais fortes nos grupos de consumo. No contexto da confraria não é diferente, o vinho torna-se o grande vínculo de união entre as mulheres. Além de proporcionar o convívio com as participantes da confraria, ele proporciona a interação com outras confrarias existentes e, ainda, com outras pessoas que também gostam ou possuem o hábito de beber vinho. $O$ relato abaixo, extraído do histórico da confraria, revela esse significado:

Não podemos esquecer que além da aprendizagem é uma oportunidade de conhecer e interagir com outras pessoas que partilham de um interesse comum. As confrarias já existentes dividem informações e auxiliam na organização das novas confrarias. Esse intercâmbio solidifica laços entre as confrarias de forma a que os encontros que se realizam periodicamente entre elas sejam oportunidades de troca de informações, bem como oportuniza novas amizades (HISTÓRICO DA CONFRARIA).

Muitas das integrantes do grupo entraram na confraria também pelo interesse social, para desfrutar de uma janta com amigas, degustar vinhos e fazer amizades. As participantes vão trazendo suas amigas e conhecidas para se reunir com um objetivo em comum: o vinho. A bebida, então, assume o papel de viabilizar essa socialização.

\section{FAMÍLIA}

Para muitas das confreiras, o vinho possui um significado familiar, similar a nostalgia que muitas sentem em relação a sua infância. Além dos hábitos familiares, o contato direto com a uva proporcionado pela infância passada em uma região vitivinícola também tornou o vinho um elemento familiar. Da mesma forma com que o vinho simboliza a família no sentido das lembranças e recordações do passado, hoje ele também serve de meio para reunir a família, perpetuando a tradição familiar. O depoimento de Maria Alice, a seguir, expressa essa relação do vinho e a família.

Hoje acontece muito lá em casa nos domingos, porque todo mundo vai almoçar lá, então aí, "ah, que vinho vai tomar", aí todo mundo leva um vinho, ou então pega um lá embaixo, se o vinho não tá bom aí a gente já deixa para fazer comida [...] é ótimo pois toda a família se envolve com a escolha dos vinhos (M ALICE). 


\section{HOBBY}

O interesse pelo vinho para muitas confreiras é tão grande, que elas fazem dele um hobby nas suas vidas. O vinho abriu as portas para diversas áreas a ele relacionadas: a da culinária, da enogastronomia (harmonização) e até de viagens enoturísticas. O hobby de degustar vinhos engloba todos esses interesses. O significado de hobby também é evidenciado pelo grande número de mulheres da confraria que buscou outros cursos relacionados ao vinho.

Eu fiz o curso de Sommelier do Senac três anos e depois nós fundamos uma outra confraria, que é a mista agora, a confraria das quintas-feiras, que já faz mais dois anos, então são cinco anos já. Essa outra vivencia, de harmonização com alimentos foi fantástica, para mim complementou, mas enriqueceu muito a confraria das mulheres (SONIA).

\subsection{SIGNIFICADOS DO VINHO APRESENTADOS PELAS PRINCIPAIS MARCAS BRASILEIRAS E COM- PARAÇÃO COM SIGNIFICADOS DAS CONFREIRAS}

Foram identificadas doze construções simbólicas para o vinho por meio da análise do material de comunicação das marcas mencionadas no método. Os significados presentes nas propagandas e anúncios foram os seguintes: tradição, arte e criatividade, juventude, prazer e relaxamento, romance, comemoração, celebração em ocasiões comuns, diversão, hobby, sofisticação, status e afetividade.

Comparando os significados de consumo do vinho sob a ótica das participantes da confraria com as construções simbólicas identificadas por meio da publicidade das marcas nacionais, percebe-se que alguns significados são muito similares ou até mesmo iguais. É o caso do significado de hobby, que foi bem aparente entre as mulheres e também é bem explorado na mídia das vinícolas. Os símbolos de socialização e família, por sua vez, também são apresentados pela mídia, mesmo que de forma mais tímida, por meio do significado de afetividade. Já o significado de prazer foi bem aparente em ambos os lados, confraria e propagandas.

Por outro lado, percebe-se que a maioria dos significados apresentados pelas marcas não foi identificado de nenhuma forma nas consumidoras. Em contrapartida, pode-se dizer que o significado de tradição, assim como o de afetividade, está relacionado com a associação do vinho à família. E, os significados de celebração em ocasiões comuns e diversão apareceram de certa forma nas entrevistas com as confreiras, quando elas expressaram a mudança de hábito em relação ao consumo de vinhos em ocasiões simples do dia-a-dia e, no segundo caso, quando elas afirmam que o vinho relembra momentos alegres e divertidos (Quadro 3).

\begin{tabular}{|c|c|}
\hline SIGNIFICADOS CONFRARIA & SIGNIFICADOS VINÍCOLAS \\
\hline & Tradição \\
Intelectualidade & Arte e Criatividade \\
Poder & Juventude \\
Prazer & Prazer e Relaxamento \\
Desafio & Romantismo \\
Socialização & Comemoração \\
Família & Celebração em ocasiões comuns \\
Hobby & Diversão \\
& Hobby \\
& Sofisticação \\
& Status \\
& Afetividade \\
\hline
\end{tabular}

Quadro 3 - Comparativo de significados do vinho das mulheres da confraria e das vinícolas nacionais Fonte: Elaborado pelos autores com base na pesquisa de campo 


\subsection{VISÃO DOS ESPECIALISTAS}

Os principais tópicos abordados com os especialistas foram os seguintes: significados de consumo do vinho, confrarias femininas do vinho e sua dinâmica no mercado e a opinião dos especialistas sobre os significados encontrados nas etapas anteriores da pesquisa. $\mathrm{O}$ quadro a seguir apresenta o resumo do panorama geral do mercado brasileiro de vinhos, em termos de características e tendências, sob a ótica dos quatro especialistas entrevistados.

\begin{tabular}{|c|c|}
\hline EMPRESAS / PRODUTOS & CONSUMIDORES \\
\hline 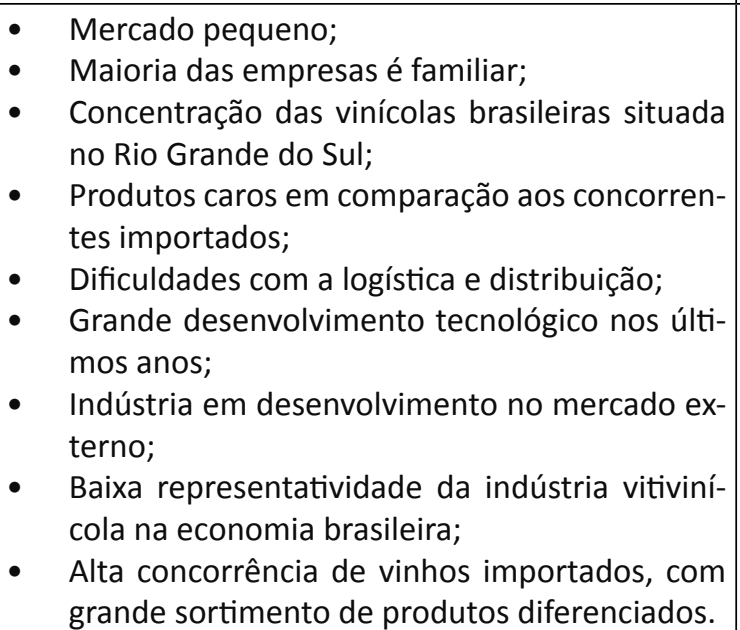 & $\begin{array}{l}\text { - } \quad \text { Aumento no consumo de espumantes; } \\
\text { Diminuição do consumo de vinhos tintos nacio- } \\
\text { nais, sendo estes substituídos por vinhos tintos } \\
\text { importados; } \\
\text { - Mudança no comportamento feminino em re- } \\
\text { lação aos vinhos, caracterizada pela maior e } \\
\text { mais efetiva participação da mulher; } \\
\text { - Falta de conhecimento dos consumidores so- } \\
\text { bre os produtos; } \\
\text { Consumidores curiosos, abertos a novas expe- } \\
\text { riências; } \\
\text { Disseminação de confrarias do vinho e cursos } \\
\text { e palestras sobre degustação e harmonização. }\end{array}$ \\
\hline
\end{tabular}

Quadro 4 - Principais características e tendências do mercado brasileiro de vinhos

Fonte: Elaborado pelos autores com base na pesquisa de campo

Foi solicitado aos entrevistados que falassem sobre os principais significados de consumo atribuídos ao vinho, de acordo com sua percepção. Conforme opinião dos especialistas, os significados de consumo do vinho são muito presentes entre os consumidores. Porém, como se dá a dinâmica deste processo no mercado ainda permanece um pouco vago entre as empresas. De acordo com os entrevistados, a maioria das vinícolas nacionais não possui uma preocupação direta, ou até mesmo a habilidade em relação aos significados de consumo, especialmente no que diz respeito a sua comunicação.

Por outro lado, outro especialista trouxe alguns exemplos sobre a empresa em que atua, a Chandon do Brasil, a qual possui uma grande preocupação em transmitir novos significados de consumo. Segundo o entrevistado, pelo fato da sua vinícola ser especializada em espumantes e este ser um produto muito restrito às comemorações de final de ano, há a necessidade de criar outras situações e significados para o seu consumo. Para a empresa, o consumo linear durante o ano é muito melhor do que o consumo sazonal. A seguir são descritos os significados de consumo do vinho citados pelos especialistas acompanhados de alguns de seus relatos: 


\begin{tabular}{|c|c|c|c|}
\hline $\begin{array}{l}\text { Qualidade da } \\
\text { vida/ slow } \\
\text { living }\end{array}$ & $\begin{array}{l}\text { No sentido do vinho } \\
\text { proporcionar uma maior } \\
\text { qualidade de vida para } \\
\text { as pessoas, em termos } \\
\text { de saúde e bem-estar }\end{array}$ & $\begin{array}{l}\text { "O vinho tem tudo a ver com a saúde, com } \\
\text { viver bem, qualidade de vida, e todos os inú- } \\
\text { meros benefícios que ele trás" }\end{array}$ & ESPECIALISTA 4 \\
\hline Família & $\begin{array}{l}\text { O vinho remete às recor- } \\
\text { dações e hábitos fami- } \\
\text { liares, além de significar } \\
\text { um momento de encon- } \\
\text { tro ou reunião da família }\end{array}$ & $\begin{array}{l}\text { "O vinho significa a família reunida, aquela } \\
\text { coisa da mesa cheia e toda a família ao redor" }\end{array}$ & ESPECIALISTA 1 \\
\hline $\begin{array}{c}\text { Prazer e } \\
\text { relaxamento }\end{array}$ & $\begin{array}{l}\text { No sentido do bem- es- } \\
\text { tar, satisfação pessoal, } \\
\text { momentos de deses- } \\
\text { tresse e relax }\end{array}$ & $\begin{array}{l}\text { "Depois acredito também que existe, mas isso } \\
\text { já é mais em casa, pelo prazer pessoal, ah vi } \\
\text { um vinho novo no supermercado, comprei, } \\
\text { vou degustar" }\end{array}$ & ESPECIALISTA 2 \\
\hline Gastronomia & $\begin{array}{l}\text { O vinho ligado à comida, } \\
\text { como complemento do } \\
\text { alimento }\end{array}$ & $\begin{array}{l}\text { "Tem pessoas que tomam o vinho por, bom, } \\
\text { um vinho com comida é um casamento per- } \\
\text { feito. O meu pai, avô e bisavô, e eu já tenho } \\
\text { isso também, uma boa refeição tem que ter } \\
\text { um vinho se não não é completa" }\end{array}$ & ESPECIALISTA 3 \\
\hline Status & $\begin{array}{l}\text { Sentimento de ascen- } \\
\text { são social, de ser bem } \\
\text { sucedido e possuir uma } \\
\text { boa imagem perante os } \\
\text { outros. }\end{array}$ & $\begin{array}{l}\text { "O vinho tem tudo a ver com charme, é como } \\
\text { se fosse uma Louis Vuitton para algumas pes- } \\
\text { soas, é querer ser chique!". }\end{array}$ & ESPECIALISTA 4 \\
\hline Comemoração & $\begin{array}{l}\text { No sentido de comemo- } \\
\text { rar datas e situações es- } \\
\text { peciais }\end{array}$ & $\begin{array}{l}\text { "[...] ou por comemoração, para celebrar um } \\
\text { momento especial" }\end{array}$ & ESPECIALISTA 3 \\
\hline Socialização & $\begin{array}{l}\text { Estar entre amigos em } \\
\text { momentos de lazer. }\end{array}$ & $\begin{array}{l}\text { o fato de estar juntos, então isso acho que } \\
\text { tem também o consumo socializando, isso é } \\
\text { muito forte no Brasil, as pessoas se encon- } \\
\text { tram, gostam dos bate papos, tá chegando, } \\
\text { esperando, vai um vinho, um espumante,um } \\
\text { petisco...do encontro social... }\end{array}$ & ESPECIALISTA 2 \\
\hline Religião & $\begin{array}{l}\text { Este significado foi tra- } \\
\text { zido por um dos espe- } \\
\text { cialistas em relação aos } \\
\text { países Europeus, não } \\
\text { sendo identificado aqui } \\
\text { no Brasil. }\end{array}$ & $\begin{array}{l}\text { O que eu observo nesses países mais tradicio- } \\
\text { nais, como Itália, França, é que, Alemanha, } \\
\text { o vinho é como se fosse uma religião. É uma } \\
\text { religião, é o envolvimento dos governos, das } \\
\text { pessoas, da comunidade, tudo vivendo em } \\
\text { cima daquele momento único da colheita da } \\
\text { uva, todo aquele histórico até chegar à uva e } \\
\text { depois colher e fazer o vinho. Tudo uma coisa, } \\
\text { uma coisa tão grande, tão mística. É uma coi- } \\
\text { sa tão impressionante prá mim. O que eu não } \\
\text { vejo, não acontece ainda no Brasil. }\end{array}$ & ESPECIALISTA 1 \\
\hline
\end{tabular}

Quadro 5 - Principais significados abordados pelos especialistas

Fonte: Elaborado pelos autores com base na pesquisa de campo

\subsubsection{Papel das Confrarias}

Para os especialistas, as confrarias possuem quatro papéis principais no mercado de vinhos:

1. Elo entre vinícolas e consumidores: consistem em um elo de comunicação e disseminação entre as vinícolas que se relacionam com elas e um grande número de consumidores participantes dos grupos; 
As empresas têm interesse em que estas pessoas venham visitar a vinícola, que tomem seus vinhos, que divulguem, claro, existe uma relação mútua, né. [...] não deixa de ser uma coisa, uma forma de divulgar seus produtos através das confrarias. [...] Tem algumas vinícolas que acham interessante esse tipo de relacionamento, algumas não dão bola! (ESPECIALISTA 1).

2. Propaganda Boca-a-boca: proporcionam a troca de experiências entre os consumidores, os quais criam o hábito de sempre compartilhar com os demais a descoberta de novos produtos e sua avaliação sobre eles; é comumente amplificada por meio das redes sociais; cabe destacar que este boca-a-boca pode ser positivo quanto negativo.

3. Desenvolvimento de novos consumidores: fazem com que pessoas que não tinha o hábito de beber vinho comecem a experimentar a bebida, se tornando novas consumidoras.

4. Educação do consumidor: desenvolvem um refinamento no consumo, fazendo com que as pessoas se tornem mais críticas e utilizem a bebida de maneira mais consciente.

Em relação à influência das confrarias na construção dos significados de consumo do vinho, todos os entrevistados afirmam que, com certeza, os grupos exercem uma grande influência na transmissão e também na criação de novos significados. O principal motivo levantado pelos especialistas é o fato da confraria educar o consumidor e desenvolver novos hábitos em relação ao vinho. Isto, com o passar do tempo, vai fazendo com que o vinho possua outros significados que antes não existiam para aquele consumidor.

\subsection{A INFLUÊNCIA DO GRUPO NO PROCESSO DE CONSTRUÇÃO DOS SIGNIFICADOS DO VINHO}

É interessante perceber que, por meio da promoção de todas essas atividades que incentivam a convivência e a relação com o vinho, a confraria exerce um papel fundamental no processo de aprendizado das mulheres. Uma das principais finalidades da confraria é: "Conhecer as origens e o processo de desenvolvimento rural e industrial da cultura do vinho na Serra Gaúcha, com o propósito de preservá-los e divulgá-los" (Cap. II, Artigo 4 - CVCM - BG). Esse conhecimento adquirido, e até, essa espécie de devoção ao vinho, vão moldando e criando os significados que as mulheres atribuem aos produtos.

Na medida em que as participantes do grupo vão conhecendo as peculiaridades e propriedades dos vinhos, mais elas parecem se inserir em um mundo repleto de significados que não existiam. O vinho sempre esteve presente na vida da grande maioria das confreiras devido, principalmente, a sua região produtora de vinhos e à cultura italiana. Porém, os significados atuais pareciam não estar presentes no, até então, mundo culturalmente constituído dessas mulheres.

O fato de todas estarem no mesmo nível de aprendizado facilita o seu envolvimento, não existe alguém que saiba tudo ou que vá ditar as regras. Mas a evolução vai ocorrendo naturalmente, de forma conjunta. Além do aprendizado, o grupo possibilita que as integrantes tenham com quem falar sobre o tema. Assim, o que fica evidente é que, além de transportar os significados dos bens para as participantes, a confraria exerce o papel de transformar esses significados, tendo inclusive o poder de modificar o mundo culturalmente constituído das mulheres. 


\section{CONSIDERAÇÕES FINAIS}

O objetivo principal deste estudo foi compreender qual é a influência da confraria feminina de vinhos na construção dos significados de consumo da bebida. Diante da ausência de pesquisas que tratassem de comunidades específicas de consumo de vinho com o intuito de tratar da dinâmica dos significados culturais de consumo, partiu-se para uma análise profunda dentro e em torno da confraria em questão.

Iniciou-se com a análise dos hábitos de consumo de vinhos das integrantes do grupo, onde foi constatado que os hábitos das mulheres antes da participação na confraria se modificavam após um tempo de vivência no grupo. $O$ ato de beber vinho torna-se desassociado a ocasiões especiais ou a companhia de outras pessoas, o que demonstra um senso de liberdade e independência por parte das mulheres. Além disso, a capacidade de avaliar o vinho por meio das próprias habilidades sensoriais, podendo inclusive harmonizá-lo com alimentos, amplia os horizontes de busca e aumenta o desejo de experimentar novas opções.

Por meio das entrevistas em profundidade e da observação participante na confraria, foi possível identificar sete construções simbólicas associadas ao vinho pelas mulheres: intelectualidade, poder, prazer, desafio, socialização, família e hobby. Talvez com exceção da família e do prazer, todos os significados foram fortemente influenciados pela vivência na confraria. Mas mesmo que não tão influenciados, como o prazer, por exemplo, todos sofreram modificações. De fato, o vinho se tornou mais importante e muito mais presente na vida dessas mulheres. São pessoas que amam o vinho entusiasticamente, muitas delas o consideram até uma extensão de sua personalidade.

No intuito de explorar quais eram os significados de consumo expostos na publicidade que permeiam o ambiente da confraria, foram analisadas as propagandas das principais marcas nacionais de vinhos, as quais coincidentemente estão localizadas no estado do Rio Grande do Sul, o que as torna ainda mais próximas do objeto de estudo. Por meio dos anúncios analisados, foram identificados doze significados de consumo do vinho: tradição, arte e criatividade, juventude, prazer e relaxamento, romance, comemoração, celebração em ocasiões comuns, diversão, hobby, sofisticação, status e afetividade.

Ao comparar os significados encontrados na publicidade com os significados identificados nas consumidoras, constatou-se que há alguns significados distintos entre as duas partes. As vinícolas maiores - como a Miolo, Salton e Aurora - demonstraram concentrar seus esforços para quebrar certos paradigmas em relação ao consumo de vinhos, ou seja, a imagem do vinho como bebida mais formal, consumida por pessoas mais velhas, em locais sofisticados e ocasiões especiais. Assim, a publicidade reflete fortemente ações voltadas para o público jovem e também a tentativa de tornar o vinho uma bebida popular em diversas ocasiões. Entretanto, há um vasto número de propagandas, destas e de outras empresas menores, que expressa o significado de tradição, enfatizando o histórico familiar e suas origens e cultura na elaboração de vinhos.

Analisando pela ótica da confraria, significados fortemente atrelados ao consumo de vinhos pelas mulheres, como o poder e o desafio, não foram observados nas propagandas. Da mesma forma, os símbolos de romantismo e sofisticação, presente nos anúncios, não apareceram entre as integrantes da confraria. Ainda, não foi identificada nenhuma propaganda direcionada especificamente para o público feminino. A única iniciativa está atingindo diretamente as mulheres, relacionando vinhos com a gastronomia e turismo, porém, não é uma ação voltada somente para a ala feminina dos consumidores, a culinária e o turismo são atividades muito praticadas também pelos homens atualmente.

Para complementar o levantamento e confirmar os achados, foram consultados quatro especialistas do mercado de vinhos. Verificou-se que o Brasil ainda está em processo de desenvolvimento da indústria vitivinícola, apesar do considerável crescimento nos últimos anos. Difi- 
culdades como preços altos, má distribuição e forte concorrência estrangeira ainda consistem em desafios para as vinícolas nacionais.

Uma forte tendência apontada pelos especialistas é a mudança no comportamento feminino em relação aos vinhos. A disseminação de confrarias do vinho e cursos sobre degustação e harmonização também foi destacada pelos entrevistados, os quais afirmam que o consumidor brasileiro em geral é curioso e aberto a novas experiências. De acordo com a visão dos especialistas, há oito significados principais para o consumo de vinhos: qualidade de vida / slow living; família, prazer e relaxamento, gastronomia, status, comemoração, socialização e religião. Apesar do conceito de significado de consumo transparecer claro entre os entrevistados, como se dá o processo de construção desses significados no mercado - das empresas para os consumidores e vice e versa- ainda parece um tanto nebuloso.

Apenas um especialista se destacou dos demais ao afirmar que a sua empresa efetivamente possui a preocupação de transmitir novos significados aos consumidores. Da mesma forma, foi o especialista que mais apresentou exemplos de estratégias de marketing que geraram sucesso em busca de novas formas de consumo do mesmo produto. As possíveis explicações podem emergir do fato de sua empresa, a Chandon do Brasil, fazem parte de um grupo mundial o qual possui uma área de marketing estruturada e bem desenvolvida. Outro motivo pelo qual a Chandon do Brasil já se mostre mais avançada em termos de comunicação de significados é a especialização somente em espumantes, os quais já quebraram a resistência do brasileiro em relação ao produto nacional.

Assim, derrubar esta oposição ao vinho brasileiro talvez ainda seja a maior preocupação das vinícolas nacionais, as quais estão focando mais nesta estratégia ao invés de investir em criar novos significados para aumentar a sua fatia de mercado. Entretanto, no contexto da confraria feminina analisada, percebe-se que as mulheres não têm mais esta preocupação ou preconceito. Nesse sentido, torna-se importante para as empresas conhecer os significados que o vinho tem para elas, sendo este o próximo passo na estratégia de marketing em que as vinícolas deveriam investir.

Os especialistas também apontaram as principais características dos grupos femininos, as quais se diferenciam das confrarias masculinas pelo fato de se focarem mais em detalhes, terem mais preocupação com a harmonização e com o aprendizado e possuírem maior apuração do olfato. Estes aspectos poderiam ser utilizados pelas empresas na definição de suas ações de marketing, as quais poderiam investir em detalhes e objetos decorativos para atrair a atenção das mulheres, por exemplo. É interessante perceber que o desejo de aprender das mulheres foi um aspecto muito aparente tanto nas entrevistas com as confreiras como nas entrevistas com os especialistas. Inclusive, pela ótica dos especialistas, esta foi a característica mais marcante apontada em relação ao público feminino.

Ao apresentar aos especialistas os significados encontrados na publicidade e nas consumidoras da confraria, houve a concordância unânime de todos em relação aos achados. $O$ que confirma mais uma vez o entendimento dos entrevistados sobre o conceito de significado de consumo e acredita os dados levantados por meio da pesquisa de campo.

Por meio deste estudo foi possível constatar que a confraria feminina exerce um papel fundamental no processo de construção dos significados do vinho. Algumas das construções simbólicas identificadas nas consumidoras possivelmente não estariam presentes se a confraria não existisse. Entretanto, se a confraria deixasse de existir hoje, provavelmente esses significados permaneceriam vivos na vida das participantes. Portanto, pode-se dizer que, neste caso, a confraria exerce um papel que extrapola o de simplesmente criar e transportar os significados do bem para o consumidor. Mas ela também acaba por modificar e transformar o mundo culturalmente constituído das mulheres, que, depois que vivem a experiência da confraria e agregam certos significados ao vinho, nunca mais serão as mesmas. 
Ainda, conforme na visão dos especialistas consultados, as confrarias, além de desenvolver novos consumidores, realizam o trabalho de educar os consumidores, o que acaba por torná-los mais abertos e mais bem preparados para receber os produtos oferecidos. Novamente isto prova que o grupo exerce grande influência e tem o poder de transformar o mundo culturalmente constituído de suas participantes, fazendo com que novos significados de consumo sejam criados.

\section{1 Implicações Acadêmicas}

Por meio dos resultados do presente estudo foi possível verificar que, na medida em que os consumidores têm o poder de criar e transformar determinados significados atribuídos a um produto (SOLOMON, 1983; THARP; SCOTT, 1990; MICK et al, 2004; MCKECHNIE; TYAN, 2006), os significados também podem surgir dentro e em torno de comunidades particulares de consumo, como uma confraria. Visto que alguns significados identificados nas participantes do grupo não possuem relação nenhuma com a publicidade, percebe-se que a interação entre os consumidores pode ser capaz de criar significados independentemente dos elementos externos.

Além disso, alguns dos novos significados criados a partir da experiência na confraria não faziam parte do mundo culturalmente constituído das mulheres anteriormente, sendo estes agregados as suas vidas de forma possivelmente permanente. Esta contribuição permite fazer um contraponto com o modelo proposto por McCracken (1986), o qual demonstra que os significados já estão presentes no mundo culturalmente constituído dos indivíduos e que eles são transportados por meio da moda, publicidade e rituais. Porém, a confraria, consistindo em um grupo, além de transportar os significados, os cria e os modifica, transformando também, o mundo cultural das mulheres que dela fazem parte.

Sendo assim, voltando às críticas já apontadas ao modelo de McCracken por outros autores, o presente estudo pode confirmá-las. Primeiramente, uma das críticas mais ressaltadas na literatura, sobre a estrutura linear rígida e unilateral do modelo, na qual a os significados devem necessariamente emergir do mundo culturalmente constituído (SOLOMON, 1983; THARP; SCOTT, 1990; MICK; BUHL, 1992; MICK et al, 2004; MCKECHNIE; TYAN, 2006) é corroborada por meio desta pesquisa. O presente estudo demonstrou que muitos dos significados identificados nas mulheres da confraria não emergiram do mundo cultural das participantes, sendo estes adquiridos após a vivência no grupo. Assim, o caminho dos significados não segue sempre a mesma direção, conforme a ideia de McCracken (1986).

Nesse sentido, este estudo confirmou a premissa de que os consumidores influenciam na significação dos bens, ou seja, concorda com a ideia de que o consumidor não é apenas um simples receptor de significado, mas ele também participa ativamente da sua construção (SOLOMON, 1983; THARP; SCOTT, 1990; MICK et al, 200; MCKECHNIE; TYAN, 2006). No caso específico da confraria, significados como: intelectualidade e desafio não foram transmitidos da publicidade ou da moda para as participantes da confraria, pelo contrário, elas próprias criaram estes significados. As propagandas investigadas não apresentaram nenhuma construção simbólica relacionada à intelectualidade ou desafio, porém, mesmo assim, esses significados se destacaram fortemente entre as consumidoras.

Outra crítica levantada por autores como Tharp e Scott (1990), Domzal e Kernan (1992); Mick e Buhl (1992); Hirshamn, Scott e Weels (1998) é inexistência da influência dos consumidores na publicidade e na moda. Nesta pesquisa verificou-se que os consumidores exercem papel fundamental no contexto da moda e publicidade que os rodeiam.

Ainda em relação à publicidade e a moda, o modelo se restringe a esses dois agentes como os únicos capazes de transferir os significados do mundo culturalmente constituído para os bens (SOLOMON, 1983; MICK et al, 2004; MCKECHNIE; TYAN, 2006). O presente estudo prova o contrário, quando se verifica que, neste caso, a própria confraria é capaz de transportar os 
significados do mundo culturalmente constituído para os bens. Sendo assim, uma subcultura de consumo também pode consistir em um agente capaz de transportar significados do mundo cultural para os bens. Da mesma forma, o modelo de McCracken (1986) indica os rituais de consumo como sendo os únicos meios de passagem dos significados dos produtos para os consumidores (SOLOMON, 1983; MICK et al, 2004; MCKECHNIE; TYAN, 2006). Entretanto, os grupos de consumo, como uma confraria do vinho, também podem consistir em transmissores de significados dos produtos para os consumidores.

Sobre a abordagem individual do consumidor na teoria de McCracken (1986), a qual não leva em consideração a influência da interação com outros indivíduos (SOLOMON, 1983; THARP; SCOTT, 1990; MICK; BUHL, 1992; MICK et al, 2004; MCKECHNIE; TYAN, 2006), este estudo vai ao encontro da concepção de que a influência da interação entre as mulheres da confraria é primordial na construção dos significados de consumo do vinho identificados individualmente em cada participante.

O presente estudo contribui com o avanço na teoria ao confirmar que a formação de um grupo específico de consumo, neste caso a confraria feminina de vinhos, é capaz de criar novos significados de consumo e modificar o mundo culturalmente constituído das consumidoras. Por fim, outra implicação acadêmica se deu pela metodologia adotada para o desenvolvimento da presente pesquisa, a qual se diferencia ao provar que é possível investigar o tema de significados culturais dos bens de consumo a partir de uma ótica não fenomenológica.

\section{2 Contribuições Gerenciais}

Embora os resultados do fenômeno investigado tenham emergido de um grupo particular de consumo, eles demonstram a existência de segmentos específicos no mercado de vinhos como o público feminino, que por meio do conhecimento e da confiança adquiridos nas confrarias, está modificando seus hábitos e participando ativamente do processo decisório de compra, e os fundadores e participantes de confrarias em geral, homens e mulheres, os quais formam opiniões e, mesmo que indiretamente, divulgam e promovem intensamente marcas e produtos. Os dois nichos consistem em inúmeras oportunidades para as empresas desenvolverem novos produtos, criarem estratégias de comunicação e de relacionamento a fim de atingir esses públicos.

Para desenvolver ainda mais o consumo do público feminino, as empresas podem se utilizar dos significados de consumo identificados nas integrantes da confraria para criar novos produtos e desenvolver a sua publicidade direcionada aos símbolos já consolidados pelas muIheres. Assim, sugere-se um alinhamento entre a visão dos significados do vinho sob a ótica das consumidoras e das propagandas das vinícolas. Por exemplo, os significados intelectualidade, poder, prazer e desafio não foram trabalhados por meio da publicidade das marcas nacionais. Uma campanha que trabalhasse com esses significados, em conjunto ou separadamente, teria uma receptividade por parte das consumidoras de vinho, uma vez que esses significados já foram construídos e internalizados no contato com a confraria. Por outro lado, os significados de arte e criatividade, juventude, romantismo, comemoração, sofisticação e status não foram até então associados pelas consumidoras como significados relevantes no consumo de vinho, isto é, a comunicação não conseguiu repassar esses signos ao mundo culturalmente constituído.

Além disso, este estudo descreveu o perfil da consumidora mulher, apontando as suas principais características e hábitos de consumo. Todas essas informações consistem em dados de grande valia para a criação de estratégias de marketing no mercado de vinhos. Em relação às confrarias do vinho, o estudo demonstrou a sua importância no mercado, indicando os seus principais papéis e demonstrando como as empresas podem fazer uso desses grupos para divulgar a 
sua marca. Em primeiro lugar, consistem em um elo entre as vinícolas e os consumidores, fazendo com que haja uma maior interação entre as partes. Consequentemente, as confrarias estão constantemente fazendo propaganda boca-a-boca, expressando suas opiniões entre os grupos, redes sociais e outros meios de comunicação. Em terceiro lugar, as confrarias são capazes de desenvolver novos consumidores, que antes não possuíam o hábito de beber vinho e, pela curiosidade gerada por meio dos grupos, acabam ingressando no mundo do vinho. Por fim, as confrarias ainda colaboram com a educação dos consumidores, os quais desenvolvem um paladar mais refinado, se tornando mais críticos e buscando produtos com padrão de qualidade mais elevado.

Outra questão elucidada foi de como as empresas podem fazer uso de comunidades de consumidores, em especial confrarias, para criar ou transformar significados de produtos cujo senso comum já está estabelecido. Por exemplo, o vinho, assim como carros, cerveja e charutos, pertence em seu sentido amplo ao universo masculino; mas por meio da confraria seus significados podem ser reconfigurados, reinterpretados e absorvidos pelo público feminino.

\section{3 Limitações e Sugestões para Estudos Futuros}

Como principal limitação para o desenvolvimento desta pesquisa, pode ser apontada a falta de estudos na literatura sobre significados de consumo do vinho. A bibliografia escassa sobre o tema específico impossibilitou a comparação da análise dos resultados com a teoria, limitando a utilização do referencial teórico à seção final de implicações acadêmicas. Em segundo lugar, em função da investigação focar em um grupo de consumo particular, localizado em uma região produtora de vinhos, a generalização dos resultados torna-se indisponível. Como terceira limitação, destaca-se a dificuldade de interpretação por parte da pesquisadora de alguns significados menos evidentes, não expressados tão claramente de maneira verbal pelas participantes da confraria.

Em relação a próximas pesquisas, seria pertinente compreender como este processo de construção de significados ocorre em contextos diferentes dos já estudados. Assim, estudos futuros poderiam analisar os significados do vinho em outros contextos, em países que apresentem um mercado mais desenvolvido e maduro, como por exemplo, Itália, França e Estados Unidos. Também seria interessante realizar um comparativo entre os países do "Velho Mundo" - onde o vinho faz parte da cultura e história das gerações - e países mais jovens, como a Austrália e a Nova Zelândia, em que a cultura do vinho tem se desenvolvido em décadas recentes.

\section{REFERÊNCIAS}

AHUVIA, Aron. C. Beyond the extended self: loved objects and consumers'identity narratives. Journal of Consumer Research, $v$. 32, n. 1, 2005.

ALTAF, J. G.; TROCCOLI, I. R.; MOREIRA, M. $B$. Você é o que você veste? A associação da autoidentidade do gay masculino ao vestuário de luxo. Revista de Administração da UFSM, v.6, 4, p. 760-782, 2013.

AMY-CHINN, Dee; JANTZEN, Christian; $\varnothing$ STERGAARD, Per. Doing and meaning: towards an integrated approach to the study of women's relationship to underwear. Journal of Consumer Culture, n. 6, 2006.

ARNOULD, Eric J.; THOMPSON, Craig J. Consumer culture theory (CCT): twenty years of research. Journal of Consumer Research, vol. 31, 2005.

AURORA - disponível em <http://www.
vinicolaaurora.com.br/>. Acesso em:
nov./2009 a fev./2011.

BARDIN, L. Análise de Conteúdo. Lisboa, Edições 70, 2000. 
BAUDRILLARD, J. A sociedade de consumo. Lisboa: Edições 70, 1981.

CASA PERINI - Disponível em <http://www. casaperini.com.br/>. Acesso em: nov./2009 a fev./2011.

CASA VALDUGA - Disponível em <http://www. casavalduga.com.br/>. Acesso em: nov./2009 a fev./2011.

CAVE GEISSE - Disponível em <http://www. cavegeisse.com.br/>. Acesso em: nov./2009 a fev./2011.

CHANDON DO BRASIL - Disponível em <http:// www. chandon.com.br/>. Acesso em: 03 mar. 2011.

CHREA, C.; MELO, L.; EVANS, G.; FORDE, C.; DELAHUNTY, C.; COX, D. N. An investigation using three approaches to understand the influence of extrinsic product cues on consumer behavior: An example of Australian wines. Journal of Sensory Studies, v. 26, n. 1, p. 13-24, 2011.

CRUZ NETO, Otávio. O trabalho de campo como descoberta e criação, In DESLANDES, S. F. NETO, O. C. MINAYO, M. C. S. Pesquisa social: teoria, método e criatividade. Petrópolis: Vozes, 1994.

DAL PIZZOL - Disponível em <http://www. dalpizzol.com.br/>. Acesso em: nov./2009 a fev./2011.

DALMORO, M. Construção de Significados Culturais Acerca dos Orgânicos: uma Análise do Mercado de Suco de Uva Orgânico. Anais do VI EMA, Gramado, 2014.

DOMZAL, Teresa; KERNAN, Jerome B. Reading advertising: the what and how of product meaning. The Journal of Consumer Marketing, v. 9, n. 3, p. 48-64, Summer 1992.

FEBAVE - Federação Brasileira de Confrarias e Associações Femininas do Vinho e do Espumante, disponível em <http://www. febave.com.br/>. Acesso em: 05 nov. 2009.

FERRAZ, S. B.; REBOUÇAS, S. M. D. P.; QUEIROZ, G. C.; ROCHA, D. C. Ser ou não ter, eis a questão: um estudo sobre materialismo e estilo de vida. Revista de Administração da UFSM, v.7, p. 2342, 2014.

GILL, R. Análise de discurso. In: BAUER, M. W.; GASKELL, G. Pesquisa qualitativa com texto, imagem e som. Petrópolis: Vozes, 2002.

HIRSCHMAN, Elizabeth C. Metaphor in the marketplace. Marketing Theory, v. 7, p. 227248, 2007.

IBRAVIN - Disponível em <http://www. ibravin. org.br/>. Acesso em: 20 jun. 2010.

LEVY, Sidney. Interpreting consumer mythology: a structural approach to consumer behavior. Journal of Marketing, v. 45, p. 49-61, 1981.

MARKS, D. Competitiveness and the Market for Central and Eastern European Wines: A Cultural Good in the Global Wine Market. Journal of Wine Research, v. 22, n. 3, 2011.

MCCRACKEN, Grant. Culture and consumption: a theoretical account of the structure and movement of the cultural meaning of consumer goods. Journal of Consumer Research, v. 13, n. 1, p. 71-84, 1986

MCCRACKEN, Grant. Cultura e consumo. Rio de Janeiro: Mauad, 2003.

MCCRACKEN, Grant. Cultura e Consumo II: mercados, significados e gerenciamento de marcas. Rio de Janeiro: Mauad, 2012.

MCKECHNIE, Sally; TYNAN, Caroline. Social meanings in Christmas consumption. Journal of Consumer Behaviour, v. 5, p. 130-144, 2006.

MERSKIN, Debra. Truly toffee and raisin hell: a textual analysis of lipstick names. Journal Sex Roles. n. 9-10, v. 56, p. 591-600, 2007.

MICK, David Glen. Consumer research and 
semiotics: exploring the morphology of signs, symbols and significance. Journal of Consumer Research, v. 13, p. 196-213, 1986.

.; BUHL, Claus. A meaning-based model of advertising experience. Journal of Consumer Research, v. 19, n. 3, p. 317-338, 1992.

.et al. Pursuing the Meaning of Meaning

in the Commercial World: an international review of marketing and consumer research founded on semiotics. Semiotica, 152 (1/4), p. 1-74, 2004.

MIOLO - disponível em <http://www. miolo. com.br/>. Acesso em: nov./2009 a fev./2011.

MOOIJ, M. ; HOFSTEDE, G. Cross-Cultural Consumer Behavior: A Review of Research Findings. Journal of International Consumer Marketing, v. 23, p. 181-192, 2011.

MUELLER, S.; LOCKSHIN, L.; SALTMAN, Y.; BLANFORD, J. Message on a bottle: The relative influence of wine back label information on wine choice. Food Quality and Preference, v. 21, n. 1, p. 22-32, 2010.

PINTO, Marcelo de Rezende. O consumo de eletrônicos em um grupo de baixa renda: relatos de uma etnografia. Revista de Administração da UFSM, v.6, 3, p. 527-545, 2013.

ROOK, Dennis W. The ritual dimension of consumer behavior. Journal of Consumer Research, v. 12, n. 3, p. 251-264, 1985.

SCOTT, Linda; WELLS, William B. A model of product discourse: linking consumer practice to cultural texts. Journal of Advertising, n. 27, v. 1, p. 33-50, 1998.

SÁENZ-NAVAJAS, M. P.; BALLESTER, J.; BALLESTER, J.; PÊCHER, C.; PEYRON, D.; VALENTIN, D. Sensory drivers of intrinsic quality of red wines: Effect of culture and level of expertise. Food Research International, v. 54, p. 1506-1518, 2013.
SÁENZ-NAVAJAS, M. P.; BALLESTER, J.; PEYRON, D.; VALENTIN, D. Extrinsic attributes responsible for red wine quality perception: A cross-cultural study between France and Spain. Food Quality and Preference, v. 35, p. 70-85, 2014.

SALTON - Disponível em <http://www. salton. com.br/>. Acesso em: nov./2009 a fev./2011.

SOLOMON, Michael R. The role of products as social stimuli: a symbolic interactionism perspective. Journal of Consumer Research, v. 10, p. 319-329, 1983.

THARP, Marye; SCOTT, Linda M. The role of marketing process in creating cultural. Journal of Macromarketing, p. 47-60, 1990.

TIAN, Kelly; BELK, Russel W. Extended self and possessions in the workplace. Journal of Consumer Research, v. 32, n. 2, 2005.

TORRI, L.; NOBLE, A. C.; HEYMANN, H. Exploring American and Italian consumer preferences for Californian and Italian red wines. Journal of the Science of Food and Agriculture, v. 93, p. 1852-1857, 2013.

VELLIQUETTE, Anne M.; MURRAY, Jeff B.; CREYER, Elizabeth $\mathrm{H}$. The tattoo renaissance: an ethnographic account of symbolic consumer behavior. Advances in Consumer Research. V. 25, p. 461-467, 1998.

VEALE, R.; QUESTER, P. Do consumer expectations match experience? Predicting the influence of price and country of origin on perceptions of product quality. International Business Review, v. 18, n. 2, p. 134-144, 2009.

WATTANASUWAN, Kritsadarat. The self and symbolic consumption. Journal of American Academy of Business, Cambridge; Mar 2005.

WELLS, William d. Three useful ideas. Advances in Consumer Research, v. 13, p. 9-11, 1986.

WESTPHAL, C.; ACEVEDO, C. R. A Construção de Significados em Subculturas de Consumo na 
Interação com os Meios de Comunicação: Uma Antropologia Aplicada ao Marketing. Anais do VI EMA, Gramado, 2014.

WILLIAMSON, P. O.; ROBICHAUD, J.; FRANCIS, I. L. Comparison of Chinese and Australian consumers' liking responses for red wines. Australian Journal of Grape and Wine Research, v. 18, p. 256-267, 2012. 